\title{
MUJER MIGRANTE: ESTUDIO GONVENGIONAL DEL MARCO DE DERECHOS HUMANOS. UNA APROXIMACIÓN AL TEMA*
}

\author{
María de Montserrat PÉRez Contreras**
}

SUMARIO: I. Introducción. II. El sistema convencional de protección de los derechos de las mujeres migrantes. III. Obligaciones de los Estados parte en materia de mujer migrante. IV. Avance. V. Reflexiones finales. VI. Referencias.

\section{INTRODUCGIÓN}

El tema de la protección de los derechos humanos de las mujeres migrantes, es un tema vigente, que exige ser estudiado y trabajado ahora más que nunca ante los constantes movimientos sociales, migratorios y legislativos en la materia, lo que hace una prioridad destacar la visibilidad de la problemática que viven; ya que si bien a estas mujeres las alcanzan algunas de las medidas tomadas para prevenir, sancionar, atender y erradicar la discriminación y la violencia en el ejercicio de sus derechos, también lo es que hay una particular preocupación por responder a las necesidades concretas de este grupo vulnerable, garantizando sus derechos fundamentales en atención a sus propias circunstancias y condiciones garantizando la dignidad humana.

La Organización de las Naciones Unidas, preocupada por la situación de los migrantes, aprobó la Convención Internacional sobre la Protección de los Derechos de Todos los Trabajadores Migratorios y de sus Familiares (1990, A/RES/45/158) como único instrumento vinculatorio

* Artículo recibido el 30 de noviembre de 2018 y aceptado para su publicación el 5 de diciembre de 2018.

** ORCID: 0000-0001-7623-7416. Investigadora en el Instituto de Investigaciones Jurídicas, UNAM; licenciada en derecho por la Universidad Intercontinental. Doctora y maestra en derecho por la Universidad Nacional Autónoma de México. Temas de interés: derecho de familia, estudios de género, infancia y grupos vulnerables. Correo electrónico: montsepc@unam.mx.

Boletín Mexicano de Derecho Comparado, nueva serie, año LI, núm. 155, mayo-agosto de 2019, pp. 1221-1258. 
concreto, así como la Declaración de Nueva York sobre Refugiados y Migrantes (2016, A/RES/71/1) que, de la mano de otros instrumentos, que abordaremos en seguida, abonan las estrategias necesarias para garantizar los derechos humanos y libertades fundamentales de la mujer migrante.

Por su parte, el Comité sobre la Eliminación de Todas las Formas de Discriminación contra la Mujer (CEDAW), ${ }^{1}$ en particular sobre el caso de las mujeres migrantes, señaló: “...la urgencia de garantizar los derechos de poblaciones en mayor riesgo de vulneración tales como la población LGBTI, las mujeres indígenas y afrodescendientes, las defensoras de derechos humanos, las periodistas y las mujeres migrantes, solicitantes de asilo y refugiadas".

Se señala que las razones por las que las mujeres se encuentran migrando, por todo el mundo, tienen su origen en la pobreza en la que viven, en la necesidad de superar su calidad de vida y oportunidades, así como a otros de índole política y bélica que las obligan al igual que a sus familias a abandonar sus países de origen.

Existe preocupación en el sentido de que se ha visibilizado a una gran cantidad de mujeres, especialmente en los países emergentes, que se movilizan a través de las fronteras: "Las mujeres representan casi la mitad de los 244 millones de migrantes y la mitad de los 19,6 millones de personas refugiadas del mundo" (ONU-Mujeres s.d. a). Igualmente, a la ausencia de programas de acción y en general políticas de protección y apoyo para este grupo vulnerable de mujeres: "Sin embargo, las necesidades, las prioridades y las voces de las mujeres refugiadas y migrantes suelen estar ausentes de las políticas destinadas a protegerlas y darles asistencia” (ONUMujeres s.d. a).

El papel de las mujeres migrantes a los ojos de los representantes de la comunidad internacional, y de los propios estudios realizados por los órganos de las Naciones Unidas, ha sido definido como sigue:

1 Que como es sabido, es el órgano establecido en la Convención sobre la Eliminación de todas las Formas de Discriminación contra la Mujer para vigilar el cumplimiento de la Convención, el que examina los informes de los Estados parte y el que como consecuencia de ello formula observaciones finales con el fin de apoyar al Estado que presenta el informe a lograr aplicar las disposiciones de la Convención. También es el que elabora observaciones generales en las que señala los principales temas de preocupación y las recomendaciones sobre cómo abordar los retos que enfrentan los Estados parte en la aplicación de la Convención (véase ACNUDH s. d.a). 
En todo el mundo, las mujeres refugiadas y migrantes desempeñan un papel central como sostén de las comunidades y economías. Por esta razón, los compromisos mundiales deben incluir el logro de la igualdad de género, el empoderamiento de todas las mujeres y las niñas, y el cumplimiento de sus derechos humanos como principios subyacentes. Asimismo, deben abordar las necesidades propias de las mujeres y las niñas, incluir sus voces, y prever la rendición de cuentas ante ellas (ONU 2019).

ONU-Mujeres da cuenta de la vulnerabilidad específica de la mujer migrante la cual se refleja por conductas de discriminación, sobre la base del sexo, agravadas por factores como la pobreza, bajos niveles de educación, prejuicios culturales:

En todo el mundo, nunca antes había habido tantas mujeres migrando para mejorar su trabajo y sus vidas. Para muchas, la migración aporta estas ventajas, pero, para otras, incluye correr riesgos peligrosos, como la explotación en trabajos domésticos y la vulnerabilidad ante la violencia y la discriminación. Las políticas y prácticas de migración no han sabido reconocer a tiempo estos riesgos y adoptar medidas para que el proceso resulte seguro para las mujeres (ONU-Mujeres s.d. b).

Así es como resulta una parte fundamental de la agenda vigente de los derechos humanos de la mujer conocer sobre la situación actual que guardan los relativos a la mujer migrante (ONU-Mujeres México 2018). En virtud de lo anterior, este trabajo tiene como objetivo hacer una reseña de las Convenciones que protegen los derechos de las mujeres migrantes, una aproximación a las obligaciones de los Estados parte que resultan de ellas y a su aplicabilidad.

\section{EL SISTEMA CONVENCIONAL DE PROTECGIÓN DE LOS DERECHOS DE LAS MUJERES MIGRANTES}

Resulta fundamental comprender que la problemática de las mujeres migrantes encuentra protección y seguimiento a través de diversos instrumentos internacionales por la dinámica del fenómeno.

Dentro del sistema universal y regional de derechos humanos podemos señalar como un marco de protección para las mujeres migrantes el que incluye a la Declaración Universal de Derechos Humanos, el Pac- 
to Internacional de Derechos Civiles y Políticos; el Pacto Internacional de Derechos Económicos, Sociales y Culturales, la Convención Internacional sobre la Eliminación de Toda Forma de Discriminación contra la Mujer; la Convención contra la Tortura y Otros Tratos, o Penas Crueles, Inhumanos o Degradantes; la Convención sobre los Derechos del Niño; la Convención Internacional sobre la Protección de los Derechos de Todos los Trabajadores Migratorios y de sus Familiares; la Convención sobre los Derechos de las Personas con Discapacidad; la Convención Internacional para la Protección de Todas las Personas contra la Desaparición Forzada, la Convención sobre el Estatuto de los Refugiados de 1951 y su Protocolo; los convenios de la Organización Internacional del Trabajo relativos al Trabajo Decente para las Trabajadoras y los Trabajadores Domésticos (núm. 189), los Trabajadores Migrantes (núm. 97), y sobre las Migraciones en Condiciones Abusivas y la Promoción de la Igualdad de Oportunidades y de Trato de los Trabajadores Migrantes (núm. 143); la Convención contra la Delincuencia Organizada Transnacional y sus Protocolos, incluido el Protocolo para Prevenir, Reprimir y Sancionar la Trata de Personas, y otros instrumentos regionales e internacionales en la materia como la Convención Interamericana para Prevenir, Sancionar y Erradicar la Violencia contra la Mujer, y la Convención Americana sobre Derechos Humanos, por mencionar los que consideramos fundamentales.

\section{Convenciones internacionales universales de derechos humanos relacionados con mujer migrante}

Los Estados que conforman la comunidad internacional al ratificar estos instrumentos internacionales vinculatorios de derechos humanos han asumido la obligación de reconocer, proteger y promover los derechos humanos y las libertades fundamentales de las y los migrantes, es decir, sus derechos económicos, sociales, culturales, civiles y políticos, condenando cualquier forma de discriminación en su ejercicio y tomando todas las medidas que sean necesarias para el desarrollo y aplicación de políticas migratorias que garanticen el pleno desarrollo, la paz y una vida digna, en este caso, para las mujeres migrantes y sus familias. 


\section{A. Declaración Universal de los Derechos Humanos [1948, Resolución 217 A (III) de la Asamblea General] $]^{2}$}

La Declaración es producto de los trabajos realizados después de la Segunda Guerra Mundial, su objetivo fue crear los estándares de derechos humanos que los Estados deben garantizar a todos sus habitantes tomando como presupuesto la dignidad humana:

\section{Artículo 1}

Todos los seres humanos nacen libres e iguales en dignidad y derechos y, dotados como están de razón y conciencia, deben comportarse fraternalmente los unos con los otros.

Artículo 2

Toda persona tiene los derechos y libertades proclamados en esta Declaración, sin distinción alguna de raza, color, sexo, idioma, religión, opinión política o de cualquier otra índole, origen nacional o social, posición económica, nacimiento o cualquier otra condición.

Además, no se hará distinción alguna fundada en la condición política, jurídica o internacional del país o territorio de cuya jurisdicción dependa una persona, tanto si se trata de un país independiente, como de un territorio bajo administración fiduciaria, no autónomo o sometido a cualquier otra limitación de soberanía.

Artículo 3

Todo individuo tiene derecho a la vida, a la libertad y a la seguridad de su persona.

Artículo 4

Nadie estará sometido a esclavitud ni a servidumbre; la esclavitud y la trata de esclavos están prohibidas en todas sus formas.

Artículo 5

Nadie será sometido a torturas ni a penas o tratos crueles, inhumanos o degradantes.

Artículo 6

Todo ser humano tiene derecho, en todas partes, al reconocimiento de su personalidad jurídica.

Artículo 7

Todos son iguales ante la ley y tienen, sin distinción, derecho a igual protección de la ley. Todos tienen derecho a igual protección contra toda dis-

2 Adoptada por la Asamblea General de la ONU el 10 de diciembre de 1948.

Esta obra está bajo una Licencia Creative Commons Atribución-NoComercial-SinDerivar 4.0 Internacional, IIJ-UNAM. Boletín Mexicano de Derecho Comparado, núm. 155, mayo-agosto de 2019, pp. 1221-1258. 
criminación que infrinja esta Declaración y contra toda provocación a tal discriminación.

\section{Artículo 9}

Nadie podrá ser arbitrariamente detenido, preso ni desterrado.

Artículo 13

1. Toda persona tiene derecho a circular libremente y a elegir su residencia en el territorio de un Estado.

2. Toda persona tiene derecho a salir de cualquier país, incluso el propio, y a regresar a su país.

Artículo 15

1. Toda persona tiene derecho a una nacionalidad.

2. A nadie se privará arbitrariamente de su nacionalidad ni del derecho a cambiar de nacionalidad.

\section{B. El Pacto Internacional sobre Derechos Civiles y Politicos [1966, Resolución 2200 A (XXI) de la Asamblea General] ${ }^{3}$}

Este Pacto es el compromiso vinculatorio o convencional que formaliza la obligatoriedad de los países ratificantes de dar cumplimiento a lo establecido en la Declaración Internacional de Derechos Humanos, es decir, el Pacto es la forma en que se positivizó la Declaración. En términos generales, los derechos protegidos en este instrumento son: derecho a la vida, la condena de la tortura y los tratos crueles, inhumanos y degradantes, la prohibición de la esclavitud, derecho a la seguridad de la persona: protección contra el arresto y la detención arbitraria, derecho a la equidad procesal y al debido proceso, derecho a la libertad de expresión y religión.

En particular aplica a nuestro caso el artículo 2o. que establece la obligación del Estado parte a garantizar la igualdad y la no discriminación, por condición alguna, en el ejercicio, goce y disfrute de los derechos civiles y políticos:

Artículo 2o.

1. Cada uno de los Estados Partes en el presente Pacto se compromete a respetar y a garantizar a todos los individuos que se encuentren en su terri-

3 Adoptada por la Asamblea General de la ONU el 16 de diciembre de 1966, adhesión de México el 24 de marzo de 1981, publicación en el Diario Oficial de la Federación el 20 de mayo de 1981 .

Esta obra está bajo una Licencia Creative Commons

Atribución-NoComercial-SinDerivar 4.0 Internacional, IIJ-UNAM.

Boletín Mexicano de Derecho Comparado, núm. 155, mayo-agosto de 2019, pp. 1221-1258. 
torio y estén sujetos a su jurisdicción los derechos reconocidos en el presente Pacto, sin distinción alguna de raza, color, sexo, idioma, religión, opinión política o de otra índole, origen nacional o social, posición económica, nacimiento o cualquier otra condición social.

2. Cada Estado Parte se compromete a adoptar, con arreglo a sus procedimientos constitucionales y a las disposiciones del presente Pacto, las medidas oportunas para dictar las disposiciones legislativas o de otro carácter que fueren necesarias para hacer efectivos los derechos reconocidos en el presente Pacto y que no estuviesen ya garantizados por disposiciones legislativas o de otro carácter.

Con una perspectiva sobre la defensa de la igualdad del hombre y la mujer en y ante la ley podemos señalar:

Artículo 30.

Los Estados Parte en el presente Pacto se comprometen a garantizar a hombres y mujeres la igualdad en el goce de todos los derechos civiles y políticos enunciados en el presente Pacto.

Artículo 26

Todas las personas son iguales ante la ley y tienen derecho sin discriminación a igual protección de la ley. A este respecto, la ley prohibirá toda discriminación y garantizará a todas las personas protección igual y efectiva contra cualquier discriminación por motivos de raza, color, sexo, idioma, religión, opiniones políticas o de cualquier índole, origen nacional o social, posición económica, nacimiento o cualquier otra condición social.

El hecho de estar bajo la calidad de migrante ya sea regular o irregular, impone al Estado parte la obligación de, ya sea durante el tránsito o en el estado de recepción, proteger la vida y la integridad física, psicológica, sexual y en sus más amplios sentidos:

Artículo 6o.

1. El derecho a la vida es inherente a la persona humana. Este derecho estará protegido por la ley. Nadie podrá ser privado de la vida arbitrariamente.

Artículo 7 o.

Nadie será sometido a torturas ni a penas o tratos crueles, inhumanos o degradantes. En particular, nadie será sometido sin su libre consentimiento a experimentos médicos o científicos.

Artículo 8o. 
1. Nadie estará sometido a esclavitud. La esclavitud y la trata de esclavos estarán prohibidas en todas sus formas.

2. Nadie estará sometido a servidumbre.

3. a) Nadie será constreñido a ejecutar un trabajo forzoso u obligatorio;

Artículo 10

1. Toda persona privada de libertad será tratada humanamente y con el respeto debido a la dignidad inherente al ser humano.

Por cuanto hace al derecho de tránsito de las personas en su país de origen o en el de recepción, que es el tema que nos ocupa, en el caso de las mujeres migrantes, el Pacto señala:

Artículo 12

1. Toda persona que se halle legalmente en el territorio de un Estado tendrá derecho a circular libremente por él y a escoger libremente en él su residencia.

2. Toda persona tendrá derecho a salir libremente de cualquier país, incluso del propio.

3. Los derechos antes mencionados no podrán ser objeto de restricciones salvo cuando éstas se hallen previstas en la ley, sean necesarias para proteger la seguridad nacional, el orden público, la salud o la moral públicas o los derechos y libertades de terceros, y sean compatibles con los demás derechos reconocidos en el presente Pacto.

4. Nadie podrá ser arbitrariamente privado del derecho de entrar en su propio país.

Con respecto a la protección de las migrantes y sus familias, específicamente sobre el cuidado de los hijos, así como de las menores de edad no acompañadas, aplican los artículos:

Artículo 23

1. La familia es el elemento natural y fundamental de la sociedad y tiene derecho a la protección de la sociedad y del Estado.

Artículo 24

1. Todo niño tiene derecho, sin discriminación alguna por motivos de raza, color, sexo, idioma, religión, origen nacional o social, posición económica o nacimiento, a las medidas de protección que su condición de menor requiere, tanto por parte de su familia como de la sociedad y del Estado.

2. Todo niño será inscrito inmediatamente después de su nacimiento y deberá tener un nombre.

3. Todo niño tiene derecho a adquirir una nacionalidad.

Esta obra está bajo una Licencia Creative Commons

Atribución-NoComercial-SinDerivar 4.0 Internacional, IIJ-UNAM.

Boletin Mexicano de Derecho Comparado, núm. 155, mayo-agosto de 2019, pp. 1221-1258. 
Finalmente, podemos hacer referencia importante a la libertad de culto y pensamiento en su más amplio sentido, que queda protegido, independientemente de cualquier condición o circunstancia en que se encuentre la mujer migrante y su familia:

\section{Artículo 18}

1. Toda persona tiene derecho a la libertad de pensamiento, de conciencia y de religión; este derecho incluye la libertad de tener o de adoptar la religión o las creencias de su elección, así como la libertad de manifestar su religión o sus creencias, individual o colectivamente, tanto en público como en privado, mediante el culto, la celebración de los ritos, las prácticas y la enseñanza.

\section{El Pacto Internacional sobre Derechos Económicos Sociales y Culturales [1966, Resolución 2200 A (XXI) de la Asamblea General] ${ }^{4}$}

El Pacto tiene como objetivo reconocer y declarar que, una vida digna sólo se puede vivir y disfrutar si se permite a cada persona gozar de sus derechos económicos, sociales y culturales, al igual que de los civiles y políticos.

Como disposición mínima indispensable nuevamente se establece la igualdad, en las mismas condiciones, al hombre y la mujer respecto al ejercicio, goce y disfrute de los derechos reconocidos en el Pacto: "Artículo 3o. Los Estados Parte en el presente Pacto se comprometen a asegurar a los hombres y a las mujeres igual título a gozar de todos los derechos económicos, sociales y culturales enunciados en el presente Pacto".

En aras de evitar la explotación económica y/o laboral en su forma más amplia el acto establece las condiciones en que reconoce y se deben ejercer estos derechos:

Artículo 6o.

1. Los Estados Parte en el presente Pacto reconocen el derecho a trabajar, que comprende el derecho de toda persona a tener la oportunidad de ganarse la vida mediante un trabajo libremente escogido o aceptado, y tomarán medidas adecuadas para garantizar este derecho.

4 Adoptado por la Asamblea General de la ONU el 16 de diciembre de 1966, entró en vigor el 3 de enero de 1976, publicado en el Diario Oficial de la Federación el 12 de mayo de 1981 . 


\section{Artículo 7}

Los Estados Parte en el presente Pacto reconocen el derecho de toda persona al goce de condiciones de trabajo equitativas y satisfactorias que le aseguren en especial:

a) Una remuneración que proporcione como mínimo a todos los trabajadores:

i) Un salario equitativo e igual por trabajo de igual valor, sin distinciones de ninguna especie; en particular, debe asegurarse a las mujeres condiciones de trabajo no inferiores a las de los hombres, con salario igual por trabajo igual;

ii) Condiciones de existencia dignas para ellos y para sus familias conforme a las disposiciones del presente Pacto;

b) La seguridad y la higiene en el trabajo;

c) Igual oportunidad para todos de ser promovidos, dentro de su trabajo, a la categoría superior que les corresponda, sin más consideraciones que los factores de tiempo de servicio y capacidad;

d) El descanso, el disfrute del tiempo libre, la limitación razonable de las horas de trabajo y las vacaciones periódicas pagadas, así como la remuneración de los días festivos.

El pacto reconoce a la unidad familiar como el núcleo base de la sociedad y por ello mandata la protección más amplia para la mujer migrante, en este nuestro caso, y su familia, entre lo que se encuentra el acceso a un nivel adecuado de vida, el derecho a la salud, la protección contra la explotación en cualquiera de sus formas y el derecho a la educación:

Artículo 10

Los Estados Parte en el presente Pacto reconocen que:

1. Se debe conceder a la familia, que es el elemento natural y fundamental de la sociedad, la más amplia protección y asistencia posibles, especialmente para su constitución y mientras sea responsable del cuidado y la educación de los hijos a su cargo. El matrimonio debe contraerse con el libre consentimiento de los futuros cónyuges.

2. Se debe conceder especial protección a las madres durante un período de tiempo razonable antes y después del parto. Durante dicho período, a las madres que trabajen se les debe conceder licencia con remuneración o con prestaciones adecuadas de seguridad social.

3. Se deben adoptar medidas especiales de protección y asistencia en favor de todos los niños y adolescentes, sin discriminación alguna por razón de filiación o cualquier otra condición. Debe protegerse a los niños y adolescentes 
contra la explotación económica y social. Su empleo en trabajos nocivos para su moral y salud, o en los cuales peligre su vida o se corra el riesgo de perjudicar su desarrollo normal, será sancionado por la ley. Los Estados deben establecer también límites de edad por debajo de los cuales quede prohibido y sancionado por la ley el empleo a sueldo de mano de obra infantil.

Artículo 11

1. Los Estados Parte en el presente Pacto reconocen el derecho de toda persona a un nivel de vida adecuado para sí y su familia, incluso alimentación, vestido y vivienda adecuados, y a una mejora continua de las condiciones de existencia. Los Estados Parte tomarán medidas apropiadas para asegurar la efectividad de este derecho, reconociendo a este efecto la importancia esencial de la cooperación internacional fundada en el libre consentimiento.

Artículo 12

1. Los Estados Partes en el presente Pacto reconocen el derecho de toda persona al disfrute del más alto nivel posible de salud física y mental.

2. Entre las medidas que deberán adoptar los Estados Parte en el Pacto a fin de asegurar la plena efectividad de este derecho, figurarán las necesarias para:

a) La reducción de la mortinatalidad y de la mortalidad infantil, y el sano desarrollo de los niños;

b) El mejoramiento en todos sus aspectos de la higiene del trabajo y del medio ambiente;

c) La prevención y el tratamiento de las enfermedades epidémicas, endémicas, profesionales y de otra índole, y la lucha contra ellas;

d) La creación de condiciones que aseguren a todos asistencia médica y servicios médicos en caso de enfermedad.

Artículo 13

1. Los Estados Partes en el presente Pacto reconocen el derecho de toda persona a la educación. Convienen en que la educación debe orientarse hacia el pleno desarrollo de la personalidad humana y del sentido de su dignidad, y debe fortalecer el respeto por los derechos humanos y las libertades fundamentales. Convienen asimismo en que la educación debe capacitar a todas las personas para participar efectivamente en una sociedad libre, favorecer la comprensión, la tolerancia y la amistad entre todas las naciones y entre todos los grupos raciales, étnicos o religiosos, y promover las actividades de las Naciones Unidas en pro del mantenimiento de la paz.

2. Los Estados Partes en el presente Pacto reconocen que, con objeto de lograr el pleno ejercicio de este derecho: 
a) La enseñanza primaria debe ser obligatoria y asequible a todos gratuitamente;

b) La enseñanza secundaria, en sus diferentes formas, incluso la enseñanza secundaria técnica y profesional, debe ser generalizada y hacerse accesible a todos, por cuantos medios sean apropiados, y en particular por la implantación progresiva de la enseñanza gratuita.

\section{Convención Internacional sobre la Protección de los Derechos de los Trabajadores Migratorios y sus Familiares (1990, A/RES/45/158) ${ }^{5}$}

Esta Convención tiene un claro interés, su objetivo primordial es la protección de los migrantes como consecuencia de que los derechos de los trabajadores migratorios y de sus familias no han sido debidamente reconocidos por todos los Estados parte y sus habitantes y, por tanto, es fundamental que se les provea de una protección apropiada:

Teniendo presente que los problemas humanos que plantea la migración son aún más graves en el caso de la migración irregular, y convencidos por tanto de que se debe alentar la adopción de medidas adecuadas a fin de evitar y eliminar los movimientos y el tránsito clandestinos de los trabajadores migratorios, asegurándoles a la vez la protección de sus derechos humanos fundamentales (Convención Internacional sobre la Protección de los Derechos de todos los Trabajadores Migratorios y de sus Familiares 1990, Preámbulo).

Disposición fundamental, en la que se establece un principio de no discriminación y de igualdad de trato y oportunidades, independientemente del género, femenino o masculino al que pertenezca la persona migrante, o de cualquier otra condición o circunstancia, es el artículo 1 o. de la Convención:

1. La presente Convención será aplicable, salvo cuando en ella se disponga otra cosa, a todos los trabajadores migratorios y a sus familiares sin distinción alguna por motivos de sexo, raza, color, idioma, religión o convicción, opinión política o de otra índole, origen nacional, étnico o social, nacionalidad,

5 Adoptada por la Asamblea General de la ONU el 18 de diciembre de 1990, ratificada el 8 de marzo de 1999, Publicada en el Diario Oficial de la Federación el 13 de agosto de 1999 .

Esta obra está bajo una Licencia Creative Commons

Atribución-NoComercial-SinDerivar 4.0 Internacional, IIJ-UNAM.

Boletín Mexicano de Derecho Comparado, núm. 155, mayo-agosto de 2019, pp. 1221-1258. 
edad, situación económica, patrimonio, estado civil, nacimiento o cualquier otra condición.

El acceso a la movilidad de las personas migrantes es un presupuesto del acceso a una calidad de vida digna para ellos y sus familias:

Artículo 8o.

1. Los trabajadores migratorios y sus familiares podrán salir libremente de cualquier Estado, incluido su Estado de origen. Ese derecho no estará sometido a restricción alguna, salvo las que sean establecidas por ley, sean necesarias para proteger la seguridad nacional, el orden público, la salud o la moral pública o los derechos y libertades ajenos y sean compatibles con otros derechos reconocidos en la presente Parte de la Convención.

2. Los trabajadores migratorios y sus familiares tendrán derecho a regresar en cualquier momento a su Estado de origen y permanecer en él.

Otro artículo que aplica a la mujer migrante es el 9o., el cual establece la protección del derecho a la vida, en condiciones de igualdad, en y ante la ley de los trabajadores migrantes: "El derecho a la vida de los trabajadores migratorios y sus familiares estará protegido por ley".

Estos dos últimos artículos establecen el reconocimiento de los derechos a la identidad personal y nacional formal, así como el derecho a la educación de los hijos de las y los trabajadores migrantes:

Artículo 29

Todos los hijos de los trabajadores migratorios tendrán derecho a tener un nombre, al registro de su nacimiento y a tener una nacionalidad.

Artículo 30

Todos los hijos de los trabajadores migratorios gozarán del derecho fundamental de acceso a la educación en condiciones de igualdad de trato con los nacionales del Estado de que se trate. El acceso de los hijos de trabajadores migratorios a las instituciones de enseñanza preescolar o las escuelas públicas no podrá denegarse ni limitarse a causa de la situación irregular en lo que respecta a la permanencia o al empleo de cualquiera de los padres, ni del carácter irregular de la permanencia del hijo en el Estado de empleo.

Otro artículo que aplica a la mujer migrante es el que, en el mismo sentido, se refiere a la igualdad de trato, pero con relación a aspectos específicos relacionados con el derecho a la educación, la formación 
profesional y capacitación, al derecho a la vivienda, a la asistencia social y servicios de salud y los derechos a la posibilidad de instalar viviendas o servicios sociales o culturales para los migrantes, con el único requisito de que se cumpla, en su caso, con los requerimientos locales que establezca su legislación para todos los habitantes:

Artículo 43

1. Los trabajadores migratorios gozarán de igualdad de trato respecto de los nacionales del Estado de empleo en relación con:

a) El acceso a instituciones y servicios de enseñanza, con sujeción a los requisitos de admisión y otras reglamentaciones de las instituciones y servicios de que se trate;

b) El acceso a servicios de orientación profesional y colocación;

c) El acceso a servicios e instituciones de formación profesional y readiestramiento;

d) El acceso a la vivienda, con inclusión de los planes sociales de vivienda, y la protección contra la explotación en materia de alquileres;

e) El acceso a los servicios sociales y de salud, siempre que se hayan satisfecho los requisitos establecidos para la participación en los planes correspondientes;

f) $\mathrm{El}$ acceso a las cooperativas y empresas en régimen de autogestión, sin que ello implique un cambio de su condición de trabajadores migratorios y con sujeción a las normas y los reglamentos por que se rijan los órganos interesados;

g) El acceso a la vida cultural y la participación en ella.

2. Los Estados Parte promoverán condiciones que garanticen una efectiva igualdad de trato, a fin de que los trabajadores migratorios puedan gozar de los derechos enunciados en el párrafo 1 del presente artículo, siempre que las condiciones establecidas para su estancia, con arreglo a la autorización del Estado de empleo, satisfagan los requisitos correspondientes.

3. Los Estados de empleo no impedirán que un empleador de trabajadores migratorios instale viviendas o servicios sociales o culturales para ellos. Con sujeción a lo dispuesto en el artículo 70 de la presente Convención, el Estado de empleo podrá subordinar la instalación de esos servicios a los requisitos generalmente exigidos en ese Estado en relación con su instalación.

La Convención también sostiene que los migrantes deben tener derecho a mantener contacto con su país de origen, esto incluye el garantizar que ellas puedan regresar a su país de origen, la participación política de 
las migrantes en el país de origen y el derecho a transferir sus ingresos a su país de origen (Convención de las Naciones Unidas sobre los Derechos de los Migrantes 2005).

\section{E. La Convención sobre la Eliminación de Todas las Formas de Discriminación contra la Mujer (1979, A/RES/34/180) ${ }^{6}$}

La Convención tiene como objetivo principal reafirmar la igualdad de derechos del hombre y la mujer, ya que, como personas humanas, nacemos iguales en dignidad y derecho sin distinción del sexo o la identidad genérica. Sin embargo, frente a la realidad en la que se visibilizan, prácticas de discriminación contra la mujer en el reconocimiento, ejercicio y goce de sus derechos humanos y, de la certeza de que la igualdad del hombre y la mujer es un presupuesto indispensable para el desarrollo de la sociedad y la familia, la Asamblea General de Naciones Unidas adopta la Convención y sus medidas de acción y, la comunidad internacional se compromete mediante la firma y ratificación a prevenir, sancionar y erradicar la discriminación contra la mujer.

Aun cuando la Convención no hace una referencia específica a la mujer migrante, de conformidad con los apartados que la integran aplica a su caso el lograr una adecuada calidad de vida, lo que implica una vida libre de toda forma de discriminación, independientemente de su calidad migratoria. Por ello la Convención tiene un papel fundamental para el logro del reconocimiento y la protección de los derechos de la mujer migrante.

La Convención en su artículo 1o. define a la discriminación contra las mujeres:

A los efectos de la presente Convención, la expresión "discriminación contra la mujer" denotará toda distinción, exclusión o restricción basada en el sexo que tenga por objeto o resultado menoscabar o anular el reconocimiento, goce o ejercicio por la mujer, independientemente de su estado civil, sobre la base de la igualdad del hombre y la mujer, de los derechos humanos y las libertades fundamentales en las esferas política, económica, social, cultural y civil o en cualquier otra esfera.

6 Adoptada por la Asamblea General de la ONU el 18 de diciembre de 1979, ratificada el 23 de marzo de 1981 y Publicada en el Diario Oficial de la Federación el 12 de mayo de 1981 . 
Esta definición aplica indiscutiblemente a las mujeres migrantes en todo lo que atañe a los roles y al ejercicio de derechos que estos le otorgan tanto en lo público como en lo privado en cuanto a sus derechos económicos, sociales, culturales y civiles.

El artículo 2o. de la Convención resulta fundamental en la protección integral de los derechos humanos de la mujer migrante, en cuanto a que plantea las acciones para erradicar la discriminación contra la mujer en cualquier esfera y/o actividad de su vida y desarrollo:

Artículo 2o. Los Estados Parte condenan la discriminación contra la mujer en todas sus formas, convienen en seguir, por todos los medios apropiados y sin dilaciones, una política encaminada a eliminar la discriminación contra la mujer y, con tal objeto, se comprometen a:

a) Consagrar, si aún no lo han hecho, en sus constituciones nacionales y en cualquier otra legislación apropiada el principio de la igualdad del hombre y de la mujer y asegurar por ley u otros medios apropiados la realización práctica de ese principio;

b) Adoptar medidas adecuadas, legislativas y de otro carácter, con las sanciones correspondientes, que prohíban toda discriminación contra la mujer;

c) Establecer la protección jurídica de los derechos de la mujer sobre una base de igualdad con los del hombre y garantizar, por conducto de los tribunales nacionales competentes y de otras instituciones públicas, la protección efectiva de la mujer contra todo acto de discriminación;

d) Abstenerse de incurrir en todo acto o práctica de discriminación contra la mujer y velar por que las autoridades e instituciones públicas actúen de conformidad con esta obligación;

e) Tomar todas las medidas apropiadas para eliminar la discriminación contra la mujer practicada por cualesquiera personas, organizaciones o empresas;

f) Adoptar todas las medidas adecuadas, incluso de carácter legislativo, para modificar o derogar leyes, reglamentos, usos y prácticas que constituyan discriminación contra la mujer;

g) Derogar todas las disposiciones penales nacionales que constituyan discriminación contra la mujer.

La Convención obliga a los Estados parte a establecer todas las medidas que sean necesarias para lograr la igualdad, el desarrollo y la paz de las mujeres, en este caso de las mujeres migrantes en el mundo: 
Artículo 3o. Los Estados Parte tomarán en todas las esferas, y en particular en las esferas política, social, económica y cultural, todas las medidas apropiadas, incluso de carácter legislativo, para asegurar el pleno desarrollo y adelanto de la mujer, con el objeto de garantizarle el ejercicio y el goce de los derechos humanos y las libertades fundamentales en igualdad de condiciones con el hombre.

Un aspecto de primordial importancia para garantizar los derechos de la mujer migrante es la protección que se haga para prevenir, sancionar y erradicar la trata de personas y la explotación sexual: "Artículo 6o. Los Estados Parte tomarán todas las medidas apropiadas, incluso de carácter legislativo, para suprimir todas las formas de trata de mujeres y explotación de la prostitución de la mujer".

Por cuanto a la identidad nacional de la mujer migrante y de sus hijos la convención señala:

Artículo 9o.

1. Los Estados Parte otorgarán a las mujeres iguales derechos que a los hombres para adquirir, cambiar o conservar su nacionalidad. Garantizarán en particular, que ni el matrimonio con un extranjero ni el cambio de nacionalidad del marido durante el matrimonio cambien automáticamente la nacionalidad de la esposa, la conviertan en apátrida o la obliguen a adoptar la nacionalidad del cónyuge.

2. Los Estados Parte otorgarán a la mujer los mismos derechos que al hombre con respecto a la nacionalidad de sus hijos.

Establece diversas disposiciones con medidas dirigidas a garantizar el acceso a la mujer, y en nuestro caso a la mujer migrante y su familia, con arreglo a la ley a diversos derechos que ya se enunciaron en los instrumentos anteriores, como a la educación, empleo y capacitación, para evitar desventajas y prácticas como explotación y abuso derivadas de la calidad migratoria cuando así no deba ser conforme a la ley:

Artículo 10. Los Estados Partes adoptarán todas las medidas apropiadas para eliminar la discriminación contra la mujer, a fin de asegurarle la igualdad de derechos con el hombre en la esfera de la educación y en particular para asegurar, en condiciones de igualdad entre hombres y mujeres: 
h) Acceso al material informativo específico que contribuya a asegurar la salud y el bienestar de la familia, incluida la información y el asesoramiento sobre planificación de la familia.

Artículo 11. 1. Los Estados Parte adoptarán todas las medidas apropiadas para eliminar la discriminación contra la mujer en la esfera del empleo a fin de asegurar a la mujer, en condiciones de igualdad con los hombres, los mismos derechos, en particular:

a) El derecho al trabajo como derecho inalienable de todo ser humano;

f) El derecho a la protección de la salud y a la seguridad en las condiciones de trabajo, incluso la salvaguardia de la función de reproducción.

2. A fin de impedir la discriminación contra la mujer por razones de matrimonio o maternidad y asegurar la efectividad de su derecho a trabajar, los Estados Partes tomarán medidas adecuadas para:

c) Alentar el suministro de los servicios sociales de apoyo necesarios para permitir que los padres combinen las obligaciones para con la familia con las responsabilidades del trabajo y la participación en la vida pública, especialmente mediante el fomento de la creación y desarrollo de una red de servicios destinados al cuidado de los niños;

d) Prestar protección especial a la mujer durante el embarazo en los tipos de trabajos que se haya probado puedan resultar perjudiciales para ella.

Del mismo modo, aplica el reconocimiento del derecho de la mujer migrante a la igualdad en y ante la ley, especialmente en lo que se refiere al derecho de las personas a circular libremente y a la libertad para elegir residencia y domicilio:

Artículo 15. 1. Los Estados Partes reconocerán a la mujer la igualdad con el hombre ante la ley.

2. Los Estados Partes reconocerán a la mujer, en materias civiles, una capacidad jurídica idéntica a la del hombre y las mismas oportunidades para el ejercicio de esa capacidad. En particular, le reconocerán a la mujer iguales derechos para firmar contratos y administrar bienes y le dispensarán un trato igual en todas las etapas del procedimiento en las cortes de justicia y los tribunales.

3. Los Estados Partes convienen en que todo contrato o cualquier otro instrumento privado con efecto jurídico que tienda a limitar la capacidad jurídica de la mujer se considerará nulo. 
4. Los Estados Partes reconocerán al hombre y a la mujer los mismos derechos con respecto a la legislación relativa al derecho de las personas a circular libremente y a la libertad para elegir su residencia y domicilio.

\section{F. La Convención sobre la Eliminación de Todas las Formas de Discriminación Racial [1965, Resolución 2106 A (XX) de la Asamblea General] ${ }^{7}$}

En esta Convención el objetivo principal es prevenir, erradicar y tomar todas las medidas que sean necesarias contra la discriminación racial, que tiene su origen en la raza, color u origen étnico o nacional, la que es condenada y considerada injusta y peligrosa para la vida, el desarrollo, la paz y la calidad de vida de la persona humana. En su artículo primero nos define qué se debe entender por discriminación racial y sus características:

Artículo 1.- 1. En la presente Convención la expresión "discriminación racial" denotará toda distinción, exclusión, restricción o preferencia basada en motivos de raza, color, linaje u origen nacional o étnico, que tenga por objeto o por resultado anular o menoscabar el reconocimiento, goce o ejercicio, en condiciones de igualdad, de los derechos humanos y libertades fundamentales en las esferas política, económica, social, cultural o en cualquier otra esfera de la vida pública.

2. Esta Convención no se aplicará a las distinciones, exclusiones, restricciones o preferencias que haga un Estado parte en la presente Convención entre ciudadanos y no ciudadanos.

3. Ninguna de las cláusulas de la presente Convención podrá interpretarse en un sentido que afecte en modo alguno las disposiciones legales de los Estados partes sobre nacionalidad, ciudadanía o naturalización, siempre que tales disposiciones no establezcan discriminación contra ninguna nacionalidad en particular.

4. Las medidas especiales adoptadas con el fin exclusivo de asegurar el adecuado progreso de ciertos grupos raciales o étnicos o de ciertas personas que requieran la protección que puede ser necesaria con objeto de garantizarles, en condiciones de igualdad, el disfrute o ejercicio de los derechos humanos y de las libertades fundamentales no se considerarán como medidas de discriminación racial, siempre que no conduzcan, como consecuencia,

7 Adoptada por la Asamblea General de la ONU el 21 de diciembre de 1965 entrando en vigor el 4 de enero de 1969 y publicada en el Diario Oficial de la Federación el 13 de junio de 1975 . 
al mantenimiento de derechos distintos para los diferentes grupos raciales y que no se mantengan en vigor después de alcanzados los objetivos para los cuales se tomaron.

En el artículo 5o. se establece un catálogo de derechos que deben ser reconocidos y garantizados en su ejercicio y goce para todos independientemente de la raza, color, origen étnico o nacional:

Artículo 5.- En conformidad con las obligaciones fundamentales estipuladas en el artículo 2 de la presente Convención, los Estados parte se comprometen a prohibir y eliminar la discriminación racial en todas sus formas y a garantizar el derecho de toda persona a la igualdad ante la ley, sin distinción de raza, color u origen nacional o étnico, particularmente en el goce de los derechos siguientes:

a) El derecho a la igualdad de tratamiento en los tribunales y todos los demás órganos que administran justicia;

b) El derecho a la seguridad personal y a la protección del Estado contra todo acto de violencia o atentado contra la integridad personal cometido por funcionarios públicos o por cualquier individuo, grupo o institución;

c) Los derechos políticos, en particular el de tomar parte en elecciones, elegir y ser elegido, por medio del sufragio universal e igual, el de participar en el gobierno y en la dirección de los asuntos públicos en cualquier nivel, y el de acceso, en condiciones de igualdad, a las funciones públicas;

d) Otros derechos civiles, en particular:

i) El derecho a circular libremente y a elegir su residencia en el territorio de un Estado;

ii) El derecho a salir de cualquier país, incluso del propio, y a regresar a su país;

iii) El derecho a una nacionalidad;

iv) El derecho al matrimonio y a la elección del cónyuge;

...

vii) El derecho a la libertad de pensamiento, de conciencia y de religión;

viii) El derecho a la libertad de opinión y de expresión;

xi) El derecho a la libertad de reunión y de asociación pacíficas;

e) Los derechos económicos, sociales y culturales... 


\section{G. La Convención sobre los Derechos del Niño (1989, A/RES/44/25) ${ }^{8}$}

Esta convención está dirigida a promover y establecer las acciones necesarias para garantizar el desarrollo integral y la calidad de vida de niñas, niños y adolescentes, y para ello, reconoce el papel fundamental de la familia en un ambiente libre de violencia. Resulta importante tanto la formación formal como la informal, rigiéndose sobre la base de la educación para la paz, del reconocimiento y respeto a la dignidad humana, la libertad y la igualdad; en la tolerancia y en el entendimiento del bien común. Para lograr lo anterior se requiere de una protección particular o específica, que es la que provee esta Convención, que les permita alcanzar su bienestar.

La protección al derecho a la identidad personal y nacional, así como a la convivencia con sus progenitores y/o las relaciones con su familia se establece de la siguiente forma:

Artículo 7 o.

1. El niño será inscripto inmediatamente después de su nacimiento y tendrá derecho desde que nace a un nombre, a adquirir una nacionalidad y, en la medida de lo posible, a conocer a sus padres y a ser cuidado por ellos.

2. Los Estados Partes velarán por la aplicación de estos derechos de conformidad con su legislación nacional y las obligaciones que hayan contraído en virtud de los instrumentos internacionales pertinentes en esta esfera, sobre todo cuando el niño resultara de otro modo apátrida.

Artículo 8o.

1. Los Estados Partes se comprometen a respetar el derecho del niño a preservar su identidad, incluidos la nacionalidad, el nombre y las relaciones familiares de conformidad con la ley sin injerencias ilícitas.

2. Cuando un niño sea privado ilegalmente de algunos de los elementos de su identidad o de todos ellos, los Estados Partes deberán prestar la asistencia y protección apropiadas con miras a restablecer rápidamente su identidad.

Artículo 9o.

1. Los Estados Partes velarán por que el niño no sea separado de sus padres contra la voluntad de éstos, excepto cuando, a reserva de revisión judicial, las autoridades competentes determinen, de conformidad con la ley y los procedimientos aplicables, que tal separación es necesaria en el interés

8 Adoptada por la Asamblea General de la ONU el 20 de noviembre de 1989, ratificada el 21 de septiembre de 1990 y publicada en el Diario Oficial de la Federación el 25 de enero de 1991. 
superior del niño. Tal determinación puede ser necesaria en casos particulares, por ejemplo, en los casos en que el niño sea objeto de maltrato o descuido por parte de sus padres o cuando éstos viven separados y debe adoptarse una decisión acerca del lugar de residencia del niño.

2. En cualquier procedimiento entablado de conformidad con el párrafo 1 del presente artículo, se ofrecerá a todas las partes interesadas la oportunidad de participar en él y de dar a conocer sus opiniones.

3. Los Estados Partes respetarán el derecho del niño que esté separado de uno o de ambos padres a mantener relaciones personales y contacto directo con ambos padres de modo regular, salvo si ello es contrario al interés superior del niño.

4. Cuando esa separación sea resultado de una medida adoptada por un Estado Parte, como la detención, el encarcelamiento, el exilio, la deportación o la muerte (incluido el fallecimiento debido a cualquier causa mientras la persona esté bajo la custodia del Estado) de uno de los padres del niño, o de ambos, o del niño, el Estado Parte proporcionará, cuando se le pida, a los padres, al niño o, si procede, a otro familiar, información básica acerca del paradero del familiar o familiares ausentes, a no ser que ello resultase perjudicial para el bienestar del niño. Los Estados Partes se cerciorarán, además, de que la presentación de tal petición no entrañe por sí misma consecuencias desfavorables para la persona o personas interesadas.

Artículo 10

1. De conformidad con la obligación que incumbe a los Estados Parte a tenor de lo dispuesto en el párrafo 1 del artículo 9, toda solicitud hecha por un niño o por sus padres para entrar en un Estado Parte o para salir de él a los efectos de la reunión de la familia será atendida por los Estados Parte de manera positiva, humanitaria y expeditiva. Los Estados Parte garantizarán, además, que la presentación de tal petición no traerá consecuencias desfavorables para los peticionarios ni para sus familiares.

2. El niño cuyos padres residan en Estados diferentes tendrá derecho a mantener periódicamente, salvo en circunstancias excepcionales, relaciones personales y contactos directos con ambos padres. Con tal fin, y de conformidad con la obligación asumida por los Estados Partes en virtud del párrafo 1 del artículo 9, los Estados Parte respetarán el derecho del niño y de sus padres a salir de cualquier país, incluido el propio, y de entrar en su propio país. El derecho de salir de cualquier país estará sujeto solamente a las restricciones estipuladas por ley y que sean necesarias para proteger la seguridad nacional, el orden público, la salud o la moral públicas o los derechos y libertades de otras personas y que estén en consonancia con los demás derechos reconocidos por la presente Convención. 


\section{H. Convención sobre el Estatuto de los Refugiados (1951, Serie Tratados de} Naciones Unidas, núm. 2545, vol. 189)9

Este tema es relevante para la Organización de las Naciones Unidas, tanto así, que tiene un órgano encargado de este tema, la Oficina del Alto Comisionado de las Naciones Unidas para los Refugiados (ACNUR).

El organismo se encarga de trabajar para alcanzar el reconocimiento, goce y ejercicio eficaz, para los refugiados, de sus derechos humanos con la participación y compromiso de la comunidad internacional.

En este sentido, establece en sus contenidos la forma en que se protegerá a las personas que solicitan refugio, y cómo será que se garantizará su derecho a la identidad y su derecho de tránsito y residencia en el país receptor:

Artículo 26. Libertad de circulación Todo Estado Contratante concederá a los refugiados que se encuentren legalmente en el territorio el derecho de escoger el lugar de su residencia en tal territorio y de viajar libremente por él, siempre que observen los reglamentos aplicables en las mismas circunstancias a los extranjeros en general.

Artículo 27. Documentos de identidad Los Estados Contratantes expedirán documentos de identidad a todo refugiado que se encuentre en el territorio de tales Estados y que no posea un documento válido de viaje.

\section{Convención para la Represión de la Trata de Personas y de la Explotación} de la Prostitución Ajena (1949, A/RES/317)10

Los trabajos continuos de Naciones Unidas, así como el interés y preocupación permanentes de los Estados Parte, desde varias décadas atrás, por condenar y promover acciones para prevenir, sancionar y erradicar la prostitución y sus consecuencias al igual que la trata de personas para fines de prostitución llevan a la creación y adopción de esta convención,

9 Adoptada por la Asamblea General de la ONU el 28 de julio de 1951, adhesión de México el 7 de junio de 2000, y publicada en el Diario Oficial de la Federación el 25 de agosto de 2000.

10 Adoptado por la Asamblea General de la ONU el 21 de marzo de 1950, adhesión de México el 21 de febrero de 1956 y publicada en el Diario Oficial de la Federación el 19 de junio de 1956. 
en tanto que constituyen conductas que lleven implícitas violaciones a los derechos humanos y a las libertades fundamentales y a los objetivos de desarrollo, igualdad y paz para las mujeres y en nuestro caso para las mujeres migrantes:

\section{Articulo 1}

Las Partes en el presente Convenio se comprometen a castigar a toda persona que, para satisfacer las pasiones de otra:

1) Concertare la prostitución de otra persona, aun con el consentimiento de tal persona;

2) Explotare la prostitución de otra persona, aun con el consentimiento de tal persona.

Articulo 2

Las Partes en el presente Convenio se comprometen asimismo a castigar a toda persona que:

1) Mantuviere una casa de prostitución, la administrare o a sabiendas la sostuviere o participare en su financiamiento;

2) Diere o tomare a sabiendas en arriendo un edificio u otro local, o cualquier parte de estos, para explotar la prostitución ajena.

Articulo 3

En la medida en que lo permitan las leyes nacionales serán también castigadas toda tentativa de cometer las infracciones mencionadas en los artículos 1 y 2 y todo acto preparatorio de su comisión.

Articulo 4

En la medida en que lo permitan las leyes nacionales, será también punible la participación intencional en cualquiera de los actos delictuosos mencionados en los artículos 1 y 2.

En la medida en que lo permitan las leyes nacionales, los actos de participación serán considerados como infracciones distintas en todos los casos en que ello sea necesario para evitar la impunidad.

Es importante enfatizar que estas conductas son incompatibles con la dignidad de la persona humana y atentan contra la familia y la comunidad, como se desprende de instrumentos no convencionales como la resolución sobre la trata de mujeres y niñas (2004, A/RES/59/166). 


\section{Convenciones internacionales regionales de derechos humanos relacionados con mujer migrante}

La Organización de los Estados Americanos, organismo regional de derechos humanos, ha realizado un arduo trabajo por la defensa de éstos y en particular por los de las mujeres, especialmente los relativos a una vida libre de violencia y que aplican, en nuestro caso a la mujer migrante.

\section{A. Convención Americana sobre Derechos Humanos (Pacto de San Fosé, 1969)11}

La Convención es un instrumento general sobre derechos humanos y libertades fundamentales de carácter regional para el continente americano, incluyendo el Caribe. Es aprobada por la Organización de los Estados Americanos, por la Conferencia Interamericana Especializada sobre Derechos Humanos, que se llevó a cabo en San José, Costa Rica. Los artículos relacionados con el tema de mujer migrante son los siguientes:

Artículo 4o. Derecho a la Vida

1. Toda persona tiene derecho a que se respete su vida. Este derecho estará protegido por la ley y, en general, a partir del momento de la concepción. Nadie puede ser privado de la vida arbitrariamente.

2. En los países que no han abolido la pena de muerte, ésta sólo podrá imponerse por los delitos más graves, en cumplimiento de sentencia ejecutoriada de tribunal competente y de conformidad con una ley que establezca tal pena, dictada con anterioridad a la comisión del delito. Tampoco se extenderá su aplicación a delitos a los cuales no se le aplique actualmente.

3. No se restablecerá la pena de muerte en los Estados que la han abolido.

4. En Ningún caso se puede aplicar la pena de muerte por delitos políticos ni comunes conexos con los políticos.

5. No se impondrá la pena de muerte a personas que, en el momento de la comisión del delito, tuvieren menos de dieciocho años de edad o más de setenta, ni se le aplicará a las mujeres en estado de gravidez.

6. Toda persona condenada a muerte tiene derecho a solicitar la amnistía, el indulto o la conmutación de la pena, los cuales podrán ser concedidos en

11 Suscrita en San José de Costa Rica el 22 de noviembre de 1969, en la Conferencia Especializada Interamericana sobre Derechos, ratificada el 2 de marzo de 1981, publicada en el Diario Oficial de la Federación el 7 de mayo de 1981. 
todos los casos. No se puede aplicar la Pena de muerte mientras la solicitud este pendiente de decisión ante autoridad competente.

Artículo 18. Derecho al Nombre

Toda persona tiene derecho a un nombre propio y a los apellidos de sus padres o al de uno de ellos.

La ley reglamentará la forma de asegurar este derecho para todos, mediante nombres supuestos, si fuere necesario.

Artículo 19. Derechos del niño

Todo niño tiene derecho a las medidas de protección que su condición de menor requiere por parte de su familia, de la sociedad y del Estado.

Artículo 20. Derecho a la Nacionalidad

1. Toda persona tiene derecho a una nacionalidad.

2. Toda persona tiene derecho a la nacionalidad del Estado en cuyo territorio nació si no tiene derecho a otra.

3. A nadie se privará arbitrariamente de su nacionalidad ni del derecho a cambiar.

Artículo 22. Derecho de Circulación y de Residencia

1. Toda persona que se halle legalmente en el territorio de un Estado tiene derecho a circular por el mismo y, a residir en él con sujeción a las disposiciones legales.

2. Toda persona tiene derecho a salir libremente de cualquier país, inclusive del propio.

3. El ejercicio de los derechos anteriores no puede ser restringido sino en virtud de una ley, en la medida indispensable en una sociedad democrática, para prevenir infracciones penales o para proteger la seguridad nacional, la seguridad o el orden públicos, la moral o la salud públicas o los derechos y libertades de los demás.

4. El ejercicio de los derechos reconocidos en el inciso 1 puede, asimismo ser restringido por la ley, en zonas determinadas, por razones de interés público.

5. Nadie puede ser expulsado del territorio del Estado del cual es nacional, ni ser privado del derecho de ingresar en el mismo.

6. El extranjero que se halle legalmente en el territorio de un Estado Parte en la presente Convención, sólo podrá ser expulsado de él en cumplimiento de una decisión adoptada conforme a la ley.

7. Toda persona tiene el derecho de buscar y recibir asilo en territorio extranjero en caso de persecución por delitos políticos o comunes conexos con los políticos y de acuerdo con la legislación de cada Estado y los convenios internacionales. 
8. En ningún caso el extranjero puede ser expulsado o devuelto a otro país, sea o no de origen, donde su derecho a la vida o a la libertad personal está en riesgo de violación a causa de raza, nacionalidad, religión, condición social o de sus opiniones políticas.

9. Es prohibida la expulsión colectiva de extranjeros.

\section{B. Convención Interamericana para Prevenir, Sancionar y Erradicar la Violencia contra la Mujer (Convención de Belem Do Para, 1994) ${ }^{12}$}

La Comisión Interamericana de Mujeres es el órgano encargado de velar por el cumplimiento de la Convención que tiene como objetivo prevenir, sancionar y erradicar la violencia contra la mujer, ya que eliminarla es un requisito necesario para garantizar el reconocimiento, goce y ejercicio de sus derechos humanos y libertades fundamentales y así alcanzar su desarrollo individual y social. Esta Convención es la primera que se aprueba para trabajar sobre el tema y por ello un referente en la materia.

Para efectos de la protección de los derechos de las mujeres migrantes los artículos importantes a considerar son:

Artículo 3o.

Toda mujer tiene derecho a una vida libre de violencia, tanto en el ámbito público como en el privado.

Artículo 4o.

Toda mujer tiene derecho al reconocimiento, goce, ejercicio y protección de todos los derechos humanos y a las libertades consagradas por los instrumentos regionales e internacionales sobre derechos humanos. Estos derechos comprenden, entre otros:

a. el derecho a que se respete su vida;

b. el derecho a que se respete su integridad física, psíquica y moral;

c. el derecho a la libertad y a la seguridad personales;

d. el derecho a no ser sometida a torturas;

e. el derecho a que se respete la dignidad inherente a su persona y que se proteja a su familia;

f. el derecho a igualdad de protección ante la ley y de la ley;

g. el derecho a un recurso sencillo y rápido ante los tribunales competentes, que la ampare contra actos que violen sus derechos;

12 Adoptada el 9 de junio de 1994 en Belem Do Para, ratificada el 19 de junio de 1998 y publicada en el Diario Oficial de la Federación el 19 de enero de 1999. 
h. el derecho a libertad de asociación;

Articulo 6o.

El derecho de toda mujer a una vida libre de violencia incluye, entre otros:

a. el derecho de la mujer a ser libre de toda forma de discriminación, y

b. el derecho de la mujer a ser valorada y educada libre de patrones estereotipados de comportamiento y prácticas sociales y culturales basadas en conceptos de inferioridad o subordinación.

\section{OBLIGAGIONES DE LOS ESTADOS PARTE EN MATERIA DE MUJER MIGRANTE}

Los Estados deben establecer una política migratoria que esté dirigida a garantizar los derechos humanos y libertades fundamentales de las y los migrantes y sus familias, considerando las posibilidades regulatorias que se reconocen a los Estados, siempre que se tenga como marco los estándares fijados por la legislación convencional en el sistema universal y regional de derechos humanos, lo que queda plasmado en la opinión consultiva de la Corte Interamericana de Derechos Humanos (Corte IDH) OC-18/03 sección 1.2. "Obligaciones estatales en la determinación de las políticas migratorias a la luz de los instrumentos internacionales de protección de los derechos humanos".

También, se establece la obligación de protección de los migrantes, especialmente en condiciones de vulnerabilidad, particularmente los que están en situación irregular, contra las formas de violencia, racismo y de otras formas de discriminación y maltrato, especialmente las mujeres y los niños, que se sustenta en la opinión consultiva OC-18/03 sección 1.3 "Situación de vulnerabilidad en que se encuentran las personas migrantes".

Es obligación del Estado garantizar el derecho a la igualdad y a la no discriminación en y ante la ley, es decir, tanto en el aspecto normativo como en el de procuración y administración de justicia, como se plantea en la opinión consultiva OC-18/03 sección 1.3.1 "No discriminación e igual protección ante la ley", fundamental protección, ya que sobre este supuesto "descansa todo el andamiaje jurídico del orden público nacional e internacional” (párrafo 101).

Es obligación de los Estados proveer la protección de los derechos de los migrantes trabajadores, especialmente los que se encuentran en situación irregular, entendiendo que cualquier persona que realice o haya 
realizado una actividad remunerada adquiere la condición de trabajador y como resultado los derechos inherentes a un trabajador, independientemente de que se encuentre en situación de migración regular o irregular, como se señala en la opinión consultiva OC-18/03 sección 1.3.2, y además:

La calidad de migrante no es una justificación para privarla del goce y ejercicio de sus derechos humanos, entre ellos los de carácter laboral. El migrante, al asumir una relación de trabajo, adquiere derechos por ser trabajador, que deben ser reconocidos y garantizados, independientemente de su situación regular o irregular; estos derechos son consecuencia de la relación laboral (Corte IDH 2017, 20).

La obligación de proteger el derecho a la integridad personal, que consiste en la responsabilidad del Estado de proveer atención médica sin discriminación a personas migrantes, especialmente en situación irregular, en casos de emergencia; por ello resulta fundamental la información y atención sanitaria integral, haciéndolos accesibles y sin prácticas de discriminación, en los términos de las convenciones internacionales en materia de derechos humanos (Corte IDH 2017, 40).

El derecho a la libertad personal, que lleva implícito garantizar el principio de legalidad a los migrantes, así como el principio de no arbitrariedad en la privación de la libertad de los migrantes; la obligación de informar las razones de la detención o privación de la libertad a los migrantes; de igual forma, es una obligación poner al migrante detenido o privado de la libertad a disposición de autoridad judicial o administrativa competente; la obligación de revisar las medidas de detención y recursos efectivos (Corte IDH 2017, 43-57; CDHDF 201 1, 5-8).

También la obligación de acceso a la justicia, ya que se ha visto que existe una real necesidad de garantizar a las y los migrantes, independientemente de su situación migratoria, el acceso a ésta sin discriminación alguna para amparar sus derechos. Igualmente garantizar el acceso al debido proceso, incluyendo aquellos casos en que se encuentren involucrados niñas, niños y adolescentes migrantes tanto por autoridades administrativas como judiciales y relacionadas con todo esto el acceso a la defensa técnica y a la asistencia consular y a los recursos contra las resoluciones que los afectan (Corte IDH 2017, 57-70). 
La obligación de proteger a la familia de las y los migrantes, independientemente de su situación migratoria, así como los derechos de niñas, niños y adolescentes, sobre todo para prevenir en todo lo posible la separación familiar, especialmente cuando esto afecta directamente la estabilidad y bienestar de los hijos (Corte IDH 2017, 73-82).

La obligación de garantizar el derecho a la nacionalidad en el caso de los hijos de las y los migrantes sin discriminación debido a la calidad migratoria de sus madres y/o sus padres (Corte IDH 2017, 83).

También se debe reconocer el derecho a la circulación y la residencia, así como las garantías que se deben establecer y aplicar en el procedimiento de expulsión de las y los migrantes y sus familias, evitando los riesgos que ponen en peligro su vida y su libertad. Igualmente, reconocer y aplicar las garantías mínimas del migrante sujeto a expulsión o deportación y prohibición de expulsión masiva (Corte IDH 2017, 87-93).

Obligación de regular y garantizar el goce y ejercicio del derecho a la vida, que incluye el "deber de prevención frente a actos que vulneren los derechos a la vida, integridad personal y libertad personal de los migrantes, así como la prohibición de la esclavitud, la servidumbre y la trata" (Corte IDH 2013, 161).

Se ha observado la vulnerabilidad de la mujer migrante en el hecho de que son víctimas frecuentes de diversas formas de violencia y discriminación (Inmujeres 2007, 54-56, 86-89 y 100-106).

Es obligación de los Estados, como garantes de los derechos humanos, tomar las medidas, jurídicas, legislativas, administrativas, educativoculturales, económicas y todas las que sean necesarias para proteger los derechos y libertades fundamentales de las personas que se encuentren en su territorio independientemente de su situación migratoria y así prevenir, sancionar y erradicar prácticas que constituyan violaciones a derechos humanos. La debida investigación de los actos que atenten contra la vida, integridad y libertad personales de las y los migrantes, así como, la prohibición de la esclavitud, la servidumbre y la trata de estos.

\section{AVANCE}

Uno de los objetivos del desarrollo del milenio planteados y al que se da seguimiento hasta 2030, fecha en que se revisarán los avances, es el de combatir la discriminación 
contra la mujer, en este caso de la mujer migrante (ONU-Mujeres 2017), garantizar el ejercicio y goce de sus derechos civiles y políticos, asi como los económicos, sociales y culturales, lo que tiene relación directa y fundamental con la lucha contra todas las formas de violencia, así como promover la igualdad entre los sexos y el empoderamiento de la mujer (CINU México s. $d$.).

Sobre el tema de la mujer migrante y su familia, se dedica en la Declaración del Milenio (ONU 2000, A/RES/55/2) un numeral específico para fijar la preocupación y el desarrollo de programas de acción para garantizar todos sus derechos y su protección:

V. Derechos humanos, democracia y buen gobierno

Adoptar medidas para garantizar el respeto y la protección de los derechos humanos de los migrantes, los trabajadores migratorios y sus familias, eliminar los actos de racismo y xenofobia cada vez más frecuentes en muchas sociedades y promover una mayor armonía y tolerancia en todas las sociedades...

La organización de las Naciones Unidas desde su estructura y funciones, a través de la Relatora Especial sobre Violencia Contra la Mujer y del Relator Especial sobre los Derechos de los Migrantes, ha informado sobre el avance en la aplicación de las convenciones y el alcance de las metas en la efectividad de los derechos, que se refleja en la eficacia y efectividad en el reconocimiento, goce y ejercicio de los derechos humanos de las mujeres, incluyendo las mujeres migrantes.

Respecto al tema específico de la violencia y la discriminación contra la mujer, se informa que

Los derechos de la mujer ya se reconocen como derechos humanos fundamentales. La discriminación y los actos de violencia contra la mujer están en la vanguardia del discurso sobre los derechos humanos.

La Conferencia Mundial de Derechos Humanos de 1993 reconoció los derechos de la mujer como derechos humanos.

La Convención sobre la Eliminación de Todas las Formas de Discriminación contra la Mujer (CEDAW) entró en vigor en 1981 y el Comité correspondiente se estableció en 1982. La Convención, que con frecuencia se ha descrito como una declaración internacional de derechos de la mujer, ha logrado una ratificación casi universal. En 1999 se aprobó un Protocolo Facultativo de la Convención. 
En 2011 se estableció un Grupo de Trabajo sobre la Discriminación contra la Mujer en la Legislación y en la Práctica. Se trata del hito más reciente en la larga vía hacia la igualdad entre las mujeres y los hombres.

La Declaración sobre la Eliminación de la Violencia contra la Mujer, aprobada en diciembre de 1993, indica las medidas que deberían adoptar los Estados y los organismos internacionales para velar por la eliminación de todas las formas de violencia contra la mujer, tanto en la esfera pública como en la privada (ACNUDH 2013).

Por cuanto al tema de la mujer migrante, el relator señala la particular atención que se ha prestado al tema de los migrantes, sus familias y el reconocimiento y la protección de sus derechos, especialmente en el caso de los irregulares:

Ahora existe un marco internacional que reconoce los desafios a los que se enfrentan los migrantes y sus familiares, y garantiza sus derechos y los de los migrantes indocumentados.

Se calcula que 214 millones de personas viven actualmente fuera de su país de origen y muchos se han trasladado por diversos motivos, entre los cuales la búsqueda de protección y la búsqueda de oportunidades están estrechamente unidas.

Los migrantes con frecuencia ejercen trabajos sucios, peligrosos y degradantes. Aunque para algunos, la migración es una experiencia positiva y de potenciación, demasiados han de soportar violaciones de los derechos humanos, discriminación y explotación.

Los mecanismos de derechos humanos, como el Relator Especial sobre los derechos humanos de los migrantes, establecido en 1999, y la Convención Internacional sobre la Protección de los Derechos de Todos los Trabajadores Migratorios y de sus Familiares, que entró en vigor en 2003, han afirmado con claridad que, aunque los países tienen el derecho soberano de determinar las condiciones para la entrada y la permanencia en su territorio, también tienen la obligación de respetar, proteger y realizar los derechos humanos de todas las personas bajo su jurisdicción, independientemente de su nacionalidad u origen, y de su situación en materia de inmigración (ACNUDH 2013).

Otras acciones que dan cuenta del avance y aplicabilidad de las convenciones son las resoluciones emitidas para vigilar, hacer eficaz y dar seguimiento al cumplimiento a los compromisos establecidos en las mismas y, adquiridos con su firma y ratificación, entre las que podemos señalar las más recientes que reflejan el trabajo, conforme a los objetivos hacia 2030

Esta obra está bajo una Licencia Creative Commons

Atribución-NoComercial-SinDerivar 4.0 Internacional, IIJ-UNAM.

Boletín Mexicano de Derecho Comparado, núm. 155, mayo-agosto de 2019, pp. 1221-1258. 
para el desarrollo sostenible, que reconocen y refuerzan las acciones para la protección de los derechos laborales y la promoción de un ambiente de trabajo seguro para las y los trabajadores migratorios, en particular las mujeres migrantes: la resolución Violencia contra las trabajadoras migratorias (Asamblea General 2006, A/RES/60/139), que tiene como función generar la igualdad de género y el empoderamiento de las mujeres migratorias y la eliminación de la violencia que contra ellas se ejerce, estableciendo programas de acción que incluyen medidas para garantizar la inclusión y la protección social y jurídica de las mujeres migrantes durante todo su trayecto, es decir, en los países de origen, tránsito y destino, promoviendo el reconocimiento, goce y ejercicio de sus derechos humanos y la protección tanto contra la violencia como contra la explotación.

La resolución sobre la trata de mujeres y niñas (Asamblea General 2016, A/RES/71/167), señala que la trata de personas para la prostitución de mujeres, en particular, y como grupo vulnerable el de mujeres migrantes, y para el tráfico de órganos, se considera un delito y una grave violación a la dignidad humana, a los derechos humanos y libertades fundamentales, que impiden el desarrollo sostenible, es decir, alcanzar los objetivos de la agenda para 2030, entre ellos alcanzar las metas del Plan de Acción Mundial de las Naciones Unidas para Combatir la Trata de Personas. Por ello, se establece, en este instrumento, la importancia de implementar todo tipo de medidas y de acciones para prevenir, investigar y sancionar la trata de personas y prestar la atención debida a las víctimas de trata, considerando las múltiples causas económicas, sociales, políticas y culturales que ponen en riesgo a las mujeres, y en particular a las migrantes, de ilícitos de trata.

La resolución Protección de los migrantes (Asamblea General 2005, A/RES/60/169), señala la preocupación que existe por el trato injusto y discriminatorio que se ejerce contra las y los migrantes y sus familias, y fija el deber de los Estados pertenecientes a la comunidad internacional de promover, reconocer y proteger los derechos humanos y las libertades fundamentales de las y los migrantes y sus familias, independientemente de su situación migratoria, previniendo y eliminando las prácticas racismo, discriminación racial, xenofobia y otras formas de intolerancia, discriminación y esclavitud análogas que se ejercen contra las y los migrantes; así como de establecer mecanismos para que ante estos casos ellos puedan tener acceso a la justicia y a un procedimiento con los requisitos de ley. Para 
esto señala que los Estados, independientemente de su libertad para establecer sus políticas y legislación migratorias y la protección de sus fronteras, deben tomar en cuenta, respetar y aplicar el derecho internacional de derechos humanos, y así trabajar para el respeto a los derechos humanos y libertades fundamentales de las y los migrantes y sus familias. Cabe resaltar que en esta resolución se indica la importancia de los Estados al firmar y ratificar la Convención Internacional sobre la Protección de los Derechos de Todos los Trabajadores Migratorios y de sus Familiares.

La Declaración de Nueva York sobre Refugiados y Migrantes establece una serie de compromisos que llevan a trabajar por mejorar la condición de las y los migrantes y sus familias, así como, para alcanzar el reconocimiento, goce y ejercicio de los derechos humanos y libertades fundamentales por estos grupos vulnerables.

La Declaración de Nueva York para los Refugiados y los Migrantes expresa la voluntad política de los dirigentes mundiales de salvar vidas, proteger derechos y compartir la responsabilidad a escala mundial. En la Cumbre de las Naciones Unidas que se celebró el 19 de septiembre, los dirigentes mundiales manifestaron la forma en que cada país cumplirá estos compromisos, lo cual beneficiará a los refugiados, los migrantes, las personas que les ayudan y los países y las comunidades de acogida.

La Declaración de Nueva York contiene compromisos audaces destinados a resolver los problemas que afrontamos en la actualidad y preparar al mundo para hacer frente a los futuros retos. Entre ellos se incluyen:

Proteger los derechos humanos de todos los refugiados y migrantes, independientemente de su condición. Esto incluye los derechos de las mujeres y las niñas, así como promover su participación plena, fructífera e igualitaria en la búsqueda de soluciones.

Asegurar que todos los niños refugiados y migrantes estén estudiando en un plazo de unos meses después de su llegada.

Prevenir la violencia sexual y por razón de género, y responder ante ella.

Prestar apoyo a los países que rescaten, reciban y acojan a un gran número de refugiados y migrantes.

Trabajar para poner fin a la práctica de detener a los niños a los efectos de determinar su estatus migratorio.

Condenar enérgicamente la xenofobia contra los refugiados y los migrantes, y respaldar una campaña mundial para combatirla.

Reforzar la contribución positiva de los migrantes al desarrollo económico y social de los países de acogida. 
Mejorar la prestación de asistencia humanitaria y para el desarrollo en los países más afectados, en particular mediante modalidades innovadoras de soluciones financieras multilaterales, con el objetivo de subsanar todos los déficits de financiación.

Aplicar una respuesta integral para los refugiados, sobre la base de un nuevo marco que establezca la responsabilidad de los Estados Miembros, los asociados de la sociedad civil y el sistema de las Naciones Unidas, cuando se produzca un gran desplazamiento de refugiados o exista una situación prolongada de refugiados.

Encontrar nuevas viviendas para todos los refugiados que la Oficina del Alto Comisionado de las Naciones Unidas para los Refugiados haya considerado que necesitan reasentamiento; y ampliar las oportunidades de los refugiados para reasentarse en otros países mediante, por ejemplo, planes de movilidad de la mano de obra o programas educativos.

Fortalecer la gobernanza mundial de la migración incorporando a la Organización Internacional para las Migraciones en el sistema de las Naciones Unidas.

Las recomendaciones para abordar los derechos humanos de las mujeres en el Pacto Mundial para una Migración Segura, Ordenada y Regular, elaboradas por un grupo de expertos que se reunieron en Ginebra del 21 y 22 de noviembre de 2016, son un documento fundamental para el avance y mejoramiento de la situación de la mujer migrante:

Las recomendaciones siguientes destacan la necesidad de aplicar un enfoque basado en los derechos humanos y con perspectiva de género a la gobernanza de la migración, el cual respete la dignidad de todas las personas migrantes durante todas las etapas de la migración y proteja sus derechos de acuerdo con la legislación internacional, incluidos los principios de igualdad y no discriminación. Estas recomendaciones se fundamentan en la Agenda 2030 para el Desarrollo Sostenible, que a su vez se basa en la legislación internacional sobre derechos humanos y reconoce que incorporar de manera sistemática la perspectiva de género en la implementación de la Agenda 2030 resulta fundamental, e incluye en el Objetivo 5.c el compromiso de aprobar y fortalecer políticas acertadas y leyes aplicables para promover la igualdad de género y el empoderamiento de todas las mujeres y las niñas a todos los niveles (ONU-Mujeres 2017, 1-2). 


\section{REFLEXIONES FINALES}

Como se puede observar, en el sistema convencional protector de las y los migrantes y sus familias, no se observa una perspectiva de género, por ello la situación de vulnerabilidad que vive la mujer migrante se trata en instrumentos generales, aun cuando las mujeres, en lo particular, viven circunstancias de violencia y explotación que se presentan por el hecho de ser mujeres y, en este sentido, es importante considerar para su protección que constituyen una gran parte de la población migrante:

...la mayoría de las disposiciones y políticas migratorias aún carecen de un enfoque de género, ya que, tradicionalmente se consideraba a la migración como un fenómeno masculino y solo hace menos de diez años se viene reconociendo que las mujeres siempre han representado una parte significativa de la población migrante, ya sea como acompañante de los hombres o bien, como migrantes individuales (ONU Mujeres 2014).

Los instrumentos convencionales de protección de los derechos de las y los trabajadores migrantes tienen como finalidad establecer un marco de estándares que garanticen la dignidad de este grupo vulnerable, entre ellos, prevenir condiciones de vida y de trabajo inhumanas, abuso físico y sexual y trato degradante, a garantizar los derechos de los migrantes a la libertad de pensamiento, de expresión y de religión; igualmente, el acceso a la información sobre sus derechos, a asegurar su derecho a la igualdad en y ante la ley, así como el acceso a los servicios educativos y sociales para su adelanto y desarrollo (ONU 2005, 7-8). De la misma forma, dar seguimiento al cumplimiento a la efectividad del goce y ejercicio de sus derechos de sus derechos civiles, culturales, económicos y sociales, pero aún hace falta fortalecer los esfuerzos por garantizar a la mujer migrante, en lo particular, a una vida libre de discriminación y violencia (ACNUDH s.d. $\mathrm{b})$

\section{REFERENCIAS}

CINU MÉXICO (Centro de información de la ONU). s. d. "Los 8 Obetivos del Milenio" última consulta: 30 de septiembre de 2019, http://wrere. cinu.mx/minisitio/ODM8/los_o_objetivos_del_milenio/ 
Comisión Interamericana de Derechos Humanos (Corte IDH). 2013. Derechos humanos de los migrantes y otras personas en el contexto de la movilidad humana, OEA/Ser.L/V/II. Doc. 48/13, 30 de diciembre. México: Corte IDH.

Corte Interamericana de Derechos Humanos (Corte IDH). 2017. "Personas situación de migración o refugio". Cuadernillo de Jurisprudencia de la Corte Interamericana de Derechos Humanos, núm. 2. http://wrerre.corteidh. or.cr/sitios/libros/todos/docs/cuadernillo2.pdf.

Instituto Nacional de las Mujeres (InMujeres). 2007. Memoria: Mujeres afectadas por el fenómeno migratorio en México. Una aproximación desde la perspectiva de género. México: Inmujeres

Oficina del Alto Comisionado de NaGiones Unidas para los Dereahos Humanos (AGNUDH). s.d. a. "Comité para la Eliminación de la Discriminación contra la Mujer (CEDAW): Nota informativa preparada por la Oficina del Alto Comisionado para los Derechos Humanos sobre la participación de ONGs", última consulta: 30 de septiembre de 2019. https://www2.ohchr.org/english/bodies/cedaw/docs/ NGO_Participation._sp.pdf.

Oficina del Alto Comisionado de NaGiones Unidas PaRa los DeREGHOS Humanos (ACNUDH). s.d. b. "Relatora Especial sobre la violencia contra la mujer, sus causas y consecuencias", última consulta: 30 de septiembre de 2019, https://wwre.ohchr.org/SP/Issues/Women/ SRWomen/Pages/SRWomenIndex.aspx.

Oficina del Alto Comisionado de NaGiones Unidas para los Dereahos Humanos (ACNUDH). 2013. "20 años Trabajando Por Tus Derechos Humanos", https://wrere.ohchr.org/SP/NewesEents/OHC HR20/Pages/Achievements.aspx.

UNESCO. 2005. La Convención de las Naciones Unidas sobre los Derechos de los Migrantes, Colección Informativo Kit. Francia: UNESCO

ONU MuJERES MÉXICO 2018. "Buenas prácticas del proyecto «Promoción y protección de los derechos de las trabajadoras migrantes»”, última consulta: 30 de septiembre de 2019, https://mexico.unwomen.org/es/ digiteca/publicaciones/abril-2018/abril/buenas-practicas-mujeres-migrantes

ONU Mujeres. 2014. "Guía para Desarrollar Legislación Migratoria con Perspectiva de Género en México", https://www.unwomen.org/es/ digital-library/publications/2014/8/guia-para-desarrollar-legislacion-migrato ria-con-perspectiva-de-genero-en-mexico. 
ONU MuJERES. 2017. Recomendaciones para abordar los derechos humanos de las mujeres en el Pacto Mundial para una Migración Segura, Ordenada y Rregular. Nueva York: Entidad de las Naciones Unidas para la Igualdad de Género y el Empoderamiento de las Mujeres.

ONU MuJERES. s.d. a. "Mujeres refugiadas y migrantes", última consulta: 30 de septiembre de 2019, http://wwrw.unwomen.org/es/news/in-focus/ women-refugees-and-migrants

ONU MUJERES. s.d. b. "Empleo y migración", última consulta: 30 de septiembre de 2019, https://wwrw.unwomen.org/es/what-we-do/economicempowerment/employment-and-migration.

ONU. 2019. "Declaración de Nueva York", https://refugeesmigrants.un.org/ es/declaration

Relatoría Especial Sobre Trabajadores Migratorios y Miembros de sus Familias de la Comisión Interamericana de Derechos Humanos (CDHDF). 2011. Informe sobre los derechos de las personas migrantes en la Ciudad de México. México: CDHDF. 